\title{
DEL ALAMBRAdO A LAS SEMILLAS TRANSGÉNICAS. UN ANÁLISIS DE LA AGRICULTURA PAMPEANA A LA LUZ DEL PRINCIPAL SUPLEMENTO RURAL ARGENTINO (2007-2009)
}

\author{
Verónica Hendel ${ }^{1}$ \\ Universidad Nacional de Luján, CONICET - Argentina \\ vero_hendel@yahoo.com
}

http://dx.doi.org/10.5209/rev_NOMA.2014.v43.n3.49288

\begin{abstract}
Resumen
Las semillas transgénicas pueden ser consideradas como el "cultivo colonizador" del siglo XXI. $\mathrm{Si}$ el alambre actuó fundamentalmente sobre el territorio, fijando límites, creando capitales y expulsando gauchos, y el tractor incidió sobre el "elemento humano" y la relación entre el mismo y su entorno en el contexto de emergencia de una serie de discursos asociados al trabajo y el bienestar general, la intervención de las semillas transgénicas tendrá por objetivo la vida misma, la configuración de organismos vegetales y animales. En este caso, lo expulsado es el trabajador civilizado, que también podría pensarse como lo viviente humano. La tecnología expulsa a la vida del ámbito rural, y re-configura los límites entre lo humano, lo vegetal y lo animal, lo salvaje y lo civilizado, el campo y la ciudad, el hombre y la máquina. Es este último acontecimiento el que intentaremos pensar a partir de la noción de paisaje; a-partir, es decir, tomando el concepto como punto de partida para analizar un conjunto de textos que han aparecido a lo largo de los últimos años en el suplemento Rural de uno de los diarios más populares de la Argentina, durante los últimos años.
\end{abstract}

Palabras clave.- semillas transgénicas, región pampeana, paisaje

FROM BARBED WIRE TO GENETICALLY MODIFIED SEEDS. AN ANALYSIS OF AGRICULTURE IN THE PAMPAS REGION IN THE LIGHT OF ARGENTINEAN RURAL JOURNALS (2007-2009)

\begin{abstract}
Genetically modified seeds can be considered to be the "colonizing crop" of the newly born century. Going back into Argentina's history and culture, we may observe that the wire operated mainly over territory, establishing boundaries, creating capitals and expelling 'gauchos', and the tractor affected the "human element" and the relationship between the latter and its surroundings in a context marked by the emergency of a series of discourses related to labour and general wealth. The goal of genetically modified seeds' intervention may be considered as life itself, the configuration of vegetal and animal organisms. In this case, technology expels life from the rural area and redefines the boundaries between human, vegetal and animal, wild and civilized, country and city, man and machine. This is the effect of modernization that we seek to analyze. In order to do so, we will place ourselves in the Argentinean Pampas and take the concept of landscape as a starting point (Mitchell, 2002; Cosgrove, 2006; Andermann, 2000);
\end{abstract}

\footnotetext{
${ }^{1}$ Licenciada en Sociología y Doctoranda en Ciencias Sociales, Universidad de Buenos Aires. Becaria doctoral CONICET con sede de trabajo en la Universidad Nacional de Luján. Ha participado en numerosos proyectos de investigación en conjunto con organizaciones políticas y sociales del ámbito rural, tales como el Movimiento Agrario de Misiones y el Movimiento Campesino de Santiago del Estero. Su proyecto de tesis de doctorado "Síntomas de una ausencia. Acerca de la experiencia contemporánea de lo rural en la región pampeana (20072013)" aborda la problemática de la expansión del monocultivo de soja en la Región Pampeana argentina, con el fin de analizar los rasgos que adopta el capitalismo en el ámbito rural actual.
} 
this means we will use this notion to analyze a series of writings that have been published in the rural magazine of the most popular Argentina's newspaper during the last years.

Keywords.- genetically modified seeds, Pampas region, landscape

"Somos la tierra y el paisaje".

Frase escrita en una pancarta durante el conflicto entre ciertos sectores rurales y el gobierno $(2008)^{2}$

"El discurso político ha demonizado frecuentemente estas empresas [pools de siembra]. Las ha ligado además con el "modelo sojero" que también forma parte de su lista enemiga. Estas posiciones se alimentan en percepciones de carácter afectivo, ideológico o político, que se contraponen a la visión racional y productiva. [...] Tenemos que reconocer que quienes provenimos de familias agropecuarias somos sensibles a estos argumentos. Recordamos la vida social en el ambiente rural antes que gran parte de aquellos pobladores se mudaran al pueblo. Pero estamos obligados a pensar en grande y a aceptar muchos efectos de la modernidad si queremos una Argentina también grande".

Solanet, Manuel. "Conflictos de la moderna empresa agrícola". Anales 2009. Sociedad Rural Argentina.

\section{Recuerdos}

Añoranza de lo que fue, vestigios de una ausencia; el campo, ese conjunto de imágenes y narrativas fundamentales para pensar el devenir del espacio argentino, la patria, la nación. Afección, ideología, política y sensibilidad, términos asociados a aquello que ya no-es, por más que se lo convoque a escena una y otra vez. Nosotros, quienes provenimos de familias agropecuarias. Ellos, los pobladores que debieron mudarse al pueblo. Ambos, ganadores y perdedores, se reconocen protagonistas o herederos de una forma de vida social sentenciada a muerte. $Y$ entre un momento y otro, la modernidad y sus efectos, es decir, una profunda mutación de las prácticas, la maquinaria y los insumos agrícolas, la forma de vida rural, la economía, los organismos de control, la jurisprudencia y las organizaciones gremiales. Sin embargo, o tal vez a causa de ello, quienes abogan por la preeminencia de una "visión racional y productiva" del ámbito rural se autoproclaman como la encarnación posmoderna de "la tierra y el paisaje". Es la pregunta por esta encarnadura estético-discursiva y material la que guiará el presente ensayo, una inquietud que radica en el deseo de reflexionar acerca de los vestigios de aquel vínculo campo/ciudad que caracterizara al "paisaje moderno" o, mejor dicho, acerca de la función que le queda al paisaje, en tanto forma simbólica y material de mediación entre sociedad y ambiente, en el contexto actual.

Entre mediados del siglo XIX y fines del XX se sucederán una serie de grandes transformaciones que podemos ilustrar a modo de constelación a través de tres hitos: la difusión del alambrado, el tractor y las semillas transgénicas. A grandes rasgos, podemos señalar que así como el primero de ellos implicará el cercamiento de la estancia tradicional, la introducción de nuevos patrones productivos y de propiedad, y el ocaso de una cultura campesina tradicional, la difusión del tractor marcará el comienzo de un proceso de mecanización de las labores rurales que, nuevamente, incidirá sobre el modo de producción, pero sobre todo tendrá importantes consecuencias sobre los trabajadores rurales; por último, la adopción masiva de la semilla transgénica de soja, junto con una serie de nuevas prácticas y tecnologías, supondrá un proceso de concentración y diferenciación de la propiedad, un aumento de la productividad y una radical transformación del ambiente rural. No obstante, de las múltiples capas de significación que constituyen cada uno de estos acontecimientos, nuestro interés se orienta hacia un doble movimiento que parecería repetirse de modo lineal en cada uno de ellos. En primer lugar, una expulsión. Expulsión del gaucho para dar lugar a los arrieros y peones; del peón para dar lugar al trabajador civilizado (Barañao, 1965: 23); del

\footnotetext{
${ }^{2}$ Scaletta, Claudio. "La tierra y el paisaje". Página/12. CASH. 31 de mayo de 2009.
} 
trabajador civilizado para dejar lugar a la máquina. Movimiento lineal que no hace más que develar la singularidad de cada uno de esos momentos, de esas series. Y, luego, el límite. "El alambre", señala Jens Andermann, "es el límite entre topografía y tropografía". La demarcación de las propiedades cuyos límites habían sido hasta entonces difusos y la expansión hacia tierras "salvajes" se inscribe en el marco de una topografía de la nación; en forma simultánea, el gaucho expulsado es reinstalado en el territorio imaginario de la nacionalidad. Producción de espacios tropográficos, mapas imaginarios de identidades argentinas que se sostienen sobre una otredad convertida en tradición literaria, sobre desiertos que son meros efectos de escrituras anteriores (Andermann, 2000).

La aparición de los tractores, a mediados de la década de 1950, formará parte de la crisis de esa relación paisajística fundacional, de un cierto tipo de vínculo entre el campo y la ciudad, lo rural y lo urbano. Para mediados de la década del sesenta, una de las principales expresiones de esta se hallaba en los debates en torno a la relación binaria entre la agricultura y la industria, la naturaleza y la ciencia.

Este neologismo mecanización tiene, sin embargo, un significado concreto y universalmente aceptado. Se trata de definir con esta palabra todo lo relativo al hombre frente a la máquina. Para el caso que nos ocupa la aceptación involucra a toda actividad humana vinculada directa o indirectamente con la agricultura. Desde el humilde labriego que guía su arado desde la esteva, hasta el poseedor de la ciencia en un grado suficiente como para calcular y diseñar un complejo sistema mecánico, están comprendidos en el concepto amplio que se le quiere asignar al vocablo mecanización agrícola. [Barañao, T. V. "La formación de técnicos para la mecanización agrícola". IDIA. Suplemento № 14. Año 1965. INTA, Buenos Aires, p. 23.]

La introducción del tractor forma parte de una serie de innovaciones tecnológicas que se sucederán a lo largo de las décadas siguientes de la mano de la difusión en la Argentina de las premisas de aquello que se conocería como "revolución verde". El tractor coincide con la superación de una etapa de estancamiento productivo causado, en parte, por el éxodo de amplias capas de población rural hacia las ciudades durante las décadas del 30 y el 40 . Es a esa inquietud de los dueños de la tierra en torno a la retracción de la producción, a la que el Estado responderá con toda una serie de organismos y planes de promoción, difusión y facilidades para la incorporación de maquinaria. La expulsión, en este caso, es la del peón y el arriero, una expulsión-mutación en la cual resuenan los ecos de aquella otredad salvaje de fines del siglo XIX.

No debemos olvidarnos que estamos en presencia de casos de extraordinaria intuición, comparativamente hablando, respecto a trabajadores cultivados o instruidos en medios civilizados. Aquellos han vivido en contacto con la naturaleza, desprovistos en gran parte de artificios y recursos propios de otros medios y de ahí la agudización de sus sentidos y las formas de percepción con notable vivacidad. [...] Con este elemento humano se ha formado el tractorista, arador, sembrador, conductor de cosechas y de máquinas aún más complicadas. [...] Pero lo que conceptuamos importante es que la mecanización trae consigo una forma y una oportunidad para civilizar al trabajador argentino. [Barañao, $\mathrm{T}$. V. "La formación de técnicos para la mecanización agrícola". IDIA. Suplemento № 14. Año 1965. INTA, Buenos Aires, pp. 24-25]

Y un límite otro, difuso, contornos imaginarios de ciudades y campos que comienzan a desdibujarse. Pero no se trata de un movimiento simple, la preocupación por la máquina en el ámbito rural puede pensarse como síntoma de un desplazamiento de las fronteras entre lo civilizado y lo salvaje. El peón, que había reemplazado al gaucho, pasa ahora a ocupar su lugar en un espacio tropográfico que expulsa aquello asociado a la naturaleza, la intuición y la percepción. El reino de los sentidos debe dar lugar al de la instrucción y la ciencia. La naturaleza como peligro y sinónimo del desierto. Si el alambre había convertido a los pastizales en capitales, el tractor transformará a los peones en trabajadores civilizados, dignos habitantes de una nación en pleno desarrollo, ciudadanos de un Estado nación que procura el bienestar 
de las mayorías. El peón, recientemente inscripto en la jurisprudencia a través de la sanción de su Estatuto, es expulsado de la topografía nacional para ser instalado nuevamente en el espacio imaginario de una nacionalidad que lo ha re-bautizado como "el primer trabajador". Pero como decíamos previamente, se trata de una expulsión-mutación, aquello que pasa a ocupar el lugar de la otredad es su vínculo con lo natural, lo salvaje, lazo que deberá ser disciplinado a través de una serie de técnicas, mecanismos e instituciones.

Las semillas genéticamente modificadas serán el "cultivo colonizador" del siglo XXI. Si el alambre actuó fundamentalmente sobre el territorio, fijando límites, creando capitales y expulsando gauchos, y el tractor incidió sobre el "elemento humano" y la relación entre el mismo y su entorno en el contexto de emergencia de una serie de discursos asociados al trabajo y el bienestar general, la intervención de las semillas transgénicas tendrá por objetivo la vida misma ${ }^{3}$, la configuración de organismos vegetales y animales. En este caso, lo expulsado es el trabajador civilizado, que también podría pensarse como lo viviente humano. La tecnología expulsa a la vida del ámbito rural, en tanto heterogeneidad radical, y re-configura los límites entre lo humano, lo vegetal y lo animal, lo salvaje y lo civilizado, el campo y la ciudad, el hombre y la máquina. Es este último acontecimiento el que intentaremos pensar a partir de la noción de paisaje; a-partir, es decir, tomando el concepto como punto de partida para analizar un conjunto de textos que han aparecido a lo largo de los últimos años en los suplementos Revista Rural y Countries del diario Clarín. Para ello, primero trazaremos un breve recorrido a lo largo de la historia del agro, con un especial énfasis en el uso y comercialización de las semillas, en la Región Pampeana.

¿Por qué analizar los discursos del diario Clarín, es decir, del medio de comunicación más masivo y poderoso de la Argentina? En primer lugar, porque analizar sus discursos supone indagar en las bases y el fundamento de los discursos hegemónicos en torno a los nuevos modos de funcionamiento del capitalismo en el agro pampeano. Por otra parte, su vínculo con los sectores hegemónicos, y el compromiso que ha tenido con la transformación que los mismos han llevado acabo, hacen que su análisis nos permita acceder a los aspectos centrales de un pensamiento que ha resultado ser sumamente eficaz y parte fundamental de dicho proyecto. Luego del conflicto que ha comenzado a mediados del año 2008, entre los sectores rurales hegemónicos y el gobierno de Cristina Fernández de Kirchner, el análisis de este pensamiento se ha tornado indispensable para comprender la realidad y crear herramientas de acción.

\section{Paisaje, medio, población}

La problematización reciente de las nociones de "lugar", "espacio" y "territorio" en el ámbito de la filosofía, el arte y las ciencias sociales parecería haber finalmente despertado, "empujado nuevamente hacia la luz del día" (Casey, 1997: xi), esa dimensión de la experiencia que durante tanto tiempo estuvo adormecida. El largo sueño no comprende ni más ni menos que el desarrollo del pensamiento occidental moderno, etapa hegemonizada por el binomio "Tiempo-Espacio", con una importante preeminencia del primero sobre el segundo. Este nuevo despertar, cuyo comienzo podemos ubicar en la década del setenta, debe pensarse en el marco de una serie de transformaciones y nacimientos que tienen lugar durante la segunda posguerra (los procesos de descolonización y las críticas al relato unívoco y lineal de la modernidad, entre otros), en íntima vinculación con los cambios que comienzan a producirse al interior del régimen capitalista. Es en este contexto que se produce el re-surgimiento del concepto de "paisaje", en su carácter de mediación o lazo entre lo humano, lo cultural, lo social, por un lado, y lo natural, lo físico, lo biológico, por otro. La noción de paisaje guarda su potencial en su carácter híbrido y pluridisciplinario, en tanto producto de la convergencia de los aportes de la geografía, la historia del arte, la filosofía y la antropología, entre otras disciplinas. Mi interés en emplear la noción de paisaje como punto de partida para analizar las transformaciones recientes del agro pampeano radica en la posibilidad de superar la dicotomía sociedad-naturaleza en un contexto en el cual ninguna de las dos nociones parecería ser eficaz para asir "lo real". De todos modos, naturaleza y sociedad, probablemente los dos grandes

\footnotetext{
${ }^{3}$ En este sentido, dicha intervención puede pensarse como la culminación biopolítica de la 'conquista del desierto', al reunir los enfoques de épocas anteriores (sobre la tierra, sobre los cuerpos) en uno solo que atiende, sin discriminar, a 'la vida'.
} 
conceptos de la modernidad que entran en crisis a lo largo del siglo XX, yacen al interior de la noción de paisaje. He allí nuestra duda sobre su potencial actual.

Como medio de expresión cultural o cuerpo de formas simbólicas que puede ser invocado y modificado a fin de expresar significados y valores, la noción de paisaje adquiere la entidad de jeroglífico social, haciendo uso del concepto marxista del valor, en tanto expresado por el dinero. Es decir, "un medio físico y multisensorial en el cual los significados y valores culturales se encuentran codificados" (Mitchell, 2002: 15). En tanto experiencia de goce estético, el paisaje supone el reemplazo o recubrimiento de la relación afectiva y cotidiana entre la tierra y la vida social por una "connotación distanciada y de índole estética" (Cosgrove, 2006: 55). Remitiéndose a las transformaciones del régimen de tenencia y explotación de la tierra durante la transición del feudalismo al capitalismo, el paisaje es concebido como el tipo de experiencia del mundo físico propio de los grupos dominantes. Una experiencia que compensaría la materialidad y cotidianeidad "perdida" con el deleite estético de aquello que se posee a la distancia. En tanto naturalización de la propiedad, el paisaje como género sería representación y agente del proceso de expropiación de la tierra del que formó parte (Cosgrove, 1984). Si bien la distancia de los grupos dominantes con respecto a la tierra es un aspecto de la configuración del agro que perdura desde los comienzos del capitalismo, no es posible pensar que aquella distancia sea comparable a la actual. No sólo los protagonistas son otros, la naturaleza misma y lo humano ya no pueden ser analizados del mismo modo. El paisaje como proceso cultural, es concebido como "una serie de momentos o perspectivas relacionadas entre sí, y contradictorias, que coexisten y pueden ser reconocidas como una forma singular" (Hirsch, 1995). Un proceso que comprende la relación entre dos polos de la experiencia: lugar y espacio, adentro y afuera, imagen y representación, y que se encuentra inscripto en las prácticas sociales cotidianas.

Ya sea como proceso, jeroglífico o expresión ideológica, la noción de paisaje intenta dar cuenta de los modos que adopta el vínculo entre un sujeto autónomo (sociedad) y un entorno también autónomo (naturaleza) en términos de naturalización, codificación o representación. Autonomización fundante de la modernidad sobre la cual resulta necesario reflexionar ahora que lo viviente se ha vuelto fabricable y las semillas son creadas en laboratorios. En este sentido, parecería ser necesario volver sobre lo dado, los términos iniciales de la conversación, aquello que subyace para, luego sí, preguntarnos por la noción de paisaje y su función en el agro pampeano actual.

En la década del setenta, unos años después de que Henri Lefebvre volviera a ubicar la noción de espacio en el centro de los debates con el postulado de que el capitalismo, en pleno proceso de mutación, se había convertido, fundamentalmente, en una producción de espacio y tiempo sobre la cual se desplegaban las relaciones de producción, Michel Foucault comenzaba a esbozar la noción de una nueva tecnología de poder que denominaría "biopolítica". En uno de los cursos que éste dictó hacia fines de dicha década, esa forma novedosa en que a partir del siglo XVIII se había procurado racionalizar los problemas planteados a la práctica gubernamental por una nueva serie de fenómenos se enlazaba con una particular concepción del entorno. Si la biopolítica era aquella tecnología que había hecho entrar a la vida y sus mecanismos en el dominio de los cálculos explícitos, convirtiendo al poder-saber en un agente de transformación de la vida humana, el marco de racionalidad política dentro del cual estos problemas se habían manifestado y adquirido su agudeza era el del liberalismo. La preocupación por la vida suponía entonces una nueva forma de concebir lo humano. Al disciplinamiento del hombre/cuerpo se le sumaba el control del hombre/especie. Lo humano era ahora también cuerpo múltiple, problema biológico y problema de poder, y la noción de medio, artificial y natural, daba cuenta de aquello que lo rodeaba.

\section{Leyes y semillas}

"Es a través del vivir que el animal se distingue de lo inanimado. Pero, "vivir" se dice de muchas maneras, y si al menos una sola de éstas subsiste, diremos que algo vive: el pensamiento, la sensación, el movimiento y el reposo según el lugar, el movimiento según la nutrición, la destrucción y el crecimiento. Por ello, también todas las especies de vegetales nos parece que viven. Es evidente, en efecto, que los vegetales tienen en sí mismos un principio y una potencia 
tales que, a través de ellos, crecen y se destruyen en direcciones opuestas [...].Llamamos potencia nutritiva [threptikón] a esta parte del alma de la que también participan los vegetales".

Aristóteles $\left(413^{a}, 20-413 b, 8\right)$

Desde mediados del siglo XIX hasta la década de 1930 la exportación de productos agropecuarios (cereales y carne vacuna) constituyó la base principal de la economía Argentina. Los cultivos agrícolas en la región pampeana comenzaron en las últimas décadas del siglo XIX. En 1872 el área sembrada alcanzaba las 600 mil hectáreas, en 1900 llegaba a 6 millones y en 1914 ya sumaba 22 millones de hectáreas (Obschatko, 2003). Las primeras semillas que se utilizaron en el país provenían de importaciones hechas por los mismos agricultores inmigrantes, firmas privadas e instituciones oficiales sin mayor previsión técnica. Estas prácticas dieron lugar a la existencia de una gran variedad de semillas, integrada por poblaciones de diverso grado de heterogeneidad que se difundieron en distintas regiones sin ningún tipo o escasa intervención por parte de los gobiernos. Si bien la siembra de estas semillas durante décadas hizo que se produjera en ellas un cierto grado de adaptación, en el caso del trigo, por ejemplo, las mismas no dejaron de constituir "una abigarrada mezcla de distintas formas que diferían en características de ciclo vegetativo, altura de planta, tamaño, forma y color de espiga, resistencia a vuelco y desgrane, susceptibilidad a enfermedades, productividad, etc." (Harries, Ripoll; 1998).

Si bien en 1871 había tenido lugar la creación del Departamento Nacional de Agricultura, fue recién en 1898 que se creó el Ministerio de dicha actividad. Sin embargo, las semillas como preocupación y peligro emergerían a comienzos del siglo XX y la labor de mejoramiento de las mismas comenzaría recién en 1912 con la contratación del genetista inglés, Guillermo Backhouse, por parte del entonces Ministro de Agricultura, Dr. Adolfo Mujica. En relación a la importancia de la semilla, Enrique Klein, un ingeniero agrónomo alemán contratado por el gobierno argentino unos años más tarde, señala lo siguiente: Hacer entender a los agricultores las ventajas de la semilla de pedigree costó trabajo, pues atribuían al suelo todas las virtudes y desconocían el valor de la semilla ${ }^{4}$. El surgimiento, a lo largo de las décadas de 1910 y 1920, de la percepción de que la heterogeneidad de las semillas se encontraba vinculada a los bajos rendimientos medios del país, con alrededor de 700 kilogramos por hectárea, coincidió con los primeros signos de un debate en torno a cuánto y cómo se debía gobernar al agro. Alejandro Bunge (1880-1943), hijo de los fundadores del grupo Bunge \& Born y funcionario público durante diversos gobiernos, sostenía que el Estado debía tomar una actitud más activa, interviniendo para garantizar precios mínimos al productor, mejores condiciones de venta al extranjero y fijando los valores de los alimentos para el consumo interno (Bunge, 1920). Juan Álvarez (1878-1954), por su parte, cuya obra es precursora de la moderna historiografía argentina, observaba que la conformación de grandes latifundios en la región pampeana generaba una distribución muy injusta del producto agropecuario y del acceso a la propiedad territorial, generando efectos disruptivos en el tejido social. Para Álvarez, la causa de esta situación podía hallarse en la implementación de políticas liberales que habrían terminado detonando situaciones altamente conflictivas (Álvarez, 1936). Por otra parte, Miguel Ángel Cárcano (1889-1978), miembro de la "elite conservadora" de Córdoba, donde poseía grandes extensiones de tierra, también consideraba que la acción del gobierno era lenta y tardía, y que era necesario llevar a cabo una reforma del régimen agrario que incluyera: una ley general de tierras, un nuevo régimen impositivo, comunicación y transporte barato e impulsar la conformación de cooperativas de productores que faciliten el crédito (Cárcano, 1918: Volkind, 2010). Tanto la visión de Álvarez como la de Cárcano deben

\footnotetext{
4 "Los Klein, incuestionables custodios del trigo nacional". Diario La Nación, Suplemento Campo. 16 de agosto de 1997.
} 
ser analizadas a la luz de la revuelta de chacareros del año 1912, conocida como el "Grito de Alcorta". Es decir, a la luz de aquel tipo de acontecimientos que se debía evitar.

Sin embargo, paradójicamente los primeros signos del accionar del gobierno sobre las semillas traerían aparejados ciertos problemas. La calidad industrial de las semillas, tal como se comenzaban a nombrar y a valorar los atributos de las mismas, que se cultivaban hasta el año 1920, en que comenzaron a aparecer las primeras variedades de pedigree ${ }^{5}$, se caracterizaban por su aptitud de semiduros medianos que el mercado europeo aceptaba. Pero al reemplazarse por ciertas variedades blandas, importadas por el Ministerio de Agricultura, comenzó a modificarse la calidad industrial de las cosechas la cual pasó a asemejarse a la de la producción de los países europeos. Para 1930 la producción Argentina de trigos blandos era muy grande, alrededor del $60 \%$ del total, su comercialización se había tornado difícil y su calidad incluso había creado problemas en el consumo interno. Por otra parte, la crisis mundial, que había comenzado un año antes, estaba afectando fuertemente el precio de los granos. Es en este contexto que podemos observar ciertos indicios del nacimiento de un sistema jurídico disciplinario de tipificación, selección, control, y fiscalización de la semilla. El 5 de octubre de 1935, después de cinco años de debate y elaboración por parte del Congreso, se promulgará la "Ley de Granos" bajo el número 12.253.

La promulgación de la Ley 12.253 dará lugar a toda una serie de técnicas de racionalización y economía de un poder que debía ejercerse de la manera menos costosa y más abarcadora posible a través de un sistema de vigilancia, jerarquías e inspecciones. Se trataba de incrementar la fuerza útil de la semilla mediante su selección, fiscalización e identificación. El problema que se venía planteando en relación a la misma desde comienzos de siglo no era el de un poder que "gobernaba demasiado", sino más bien el de uno que "gobernaba demasiado poco", y que en esa escasez daba lugar a la disminución de la productividad de la semilla, de su potencia. Allí es cuando podemos observar a través de una serie de escritos y debates que la Ley de Granos comienza a ser concebida como un instrumento necesario y eficaz; con la capacidad de prohibir, obligar y prescribir a fin de cuidar y resguardar a esa semilla que, como decía Enrique Klein, los agricultores no sabían valorar. Una semilla que comenzaba a dar muestras de sus límites. Después de todo, la economía argentina que en ella se basaba no lo haría por mucho tiempo más. En consonancia con el contexto mundial y la abrupta baja del precio internacional de los productos agrícolas toda una concepción de la forma en que se debía organizar la actividad productiva comenzaba a entrar en crisis.

Si la semilla era fuente de vida, la ley del año 1935 se proponía intervenir en ella a modo de cuerpo, es decir, en su anatomía. Depurar, organizar, rotular y fiscalizar buscan hacer de ella una semilla más eficiente, garantizar una mayor productividad a partir de la creación de mecanismos de control y disciplinamiento. La heterogeneidad y la libertad habían demostrado no ser eficaces a los fines de lograr dichos objetivos. La constitución de una serie de procedimientos, instituciones y reglas que regularan su comportamiento, acción y circulación era percibida como necesaria. Un control centralizado y previsible ${ }^{6}$. Un control estatal que a través de la ley se arrogará

\footnotetext{
${ }^{5}$ Pedigree es un método de selección individual de plantas por medio de las generaciones segregadas y observación de genealogía (pedigree) de las plantas seleccionadas hasta la obtención de las líneas de los homocigotos. La selección por pedigree es utilizada para incorporar características cualitativas deseables en las semillas que se quiere mejorar. Es un método muy laborioso y requiere un registro extensivo.
}

${ }^{6}$ Art. 24 - Las personas o entidades a que se refiere el art. 22, cuando deseen difundir 0 comerciar variedades nuevas, estarán obligadas a comunicar al Ministerio de Agricultura con dos meses de anticipación, por lo menos, el lugar en que se efectuarán las siembras, a fin de 
las facultades de: autorizar la difusión de nuevas variedades de semilla; analizar, comprobar, fiscalizar y estudiar sus aptitudes en las distintas zonas del país; dejar constancia de las características de la variedad; registrar a los criaderos e instituciones privadas; rotularlas; formular un plan metódico de ensayos comparativos; propagar las desventajas y peligros de cultivar variedades ya existentes; confeccionar mapas de la distribución de dichas variedades y del porcentaje del área sembrada con las mismas; y aconsejar a los agricultores acerca de las variedades que se deben sembrar en cada región. Para ello creará un andamiaje institucional que incluirá una Comisión Nacional de Granos y Elevadores, un Tribunal de Fiscalización de Semillas y una División de Producción de Granos.

Sin embargo, todo este conjunto de procedimientos, instituciones y prohibiciones no lograrían impedir que la situación del agro se deteriorara y entrara en aquello que se conocería como el periodo de estancamiento del agro pampeano, es decir, dos décadas de crecimiento casi nulo de la producción agrícola. Y, coincidentemente, casi dos décadas de políticas públicas orientadas a: promover el desarrollo de la actividad industrial mediante la sustitución de importaciones, de consolidación de lo que suele denominarse "Estado de Bienestar" y de redistribución del ingreso. En el caso de la Argentina, todos estos fenómenos eran sinónimos del peronismo (1945-1955). El estancamiento del agro pampeano, etapa emblemática de su desarrollo, daría lugar a un intenso debate acerca de su naturaleza, que el trabajo del abogado Jorge Sábato, La pampa pródiga: Claves de una frustración (1980), recoge de un modo singular. Por un lado, encontramos la visión de que las divisas externas obtenidas por las exportaciones agropecuarias entre 1945 y 1955 habían sido acaparadas por los gobiernos peronistas, utilizándolas para financiar el desarrollo protegido de industrias ineficientes y para realizar una redistribución demagógica del ingreso. Por otra parte, hallamos una postura más heterogénea, tanto en sus argumentos como en sus partidarios, que se centraba en las trabas que la estructura de la propiedad rural pampeana habría generado al desarrollo de la región, es decir, en la perniciosa y desmedida influencia que los grandes terratenientes pampeanos habrían ejercido sobre los gobiernos. Sin embargo, Jorge Sábato sostiene que ninguna de las dos posturas brinda una respuesta adecuada al problema en cuestión y le asigna un rol fundamental a una conjunción de procesos: la presencia en los productores de una racionalidad que buscaría maximizar las ganancias y evitar el riesgo a través de una diversificación productiva (entre la ganadería y la actividad agrícola), lo cual supondría una baja incorporación e inversión en tecnología para evitar todo tipo de especialización; y la brusca reducción de la oferta de mano de obra temporaria que, vinculada al aumento de la demanda en el sector industrial, le habría puesto un nuevo "techo" a la actividad agropecuaria. "En el fondo ambas posiciones parecen sobrestimar la capacidad (negativa) del peronismo para conseguir un efecto que no habían tenido dos guerras mundiales y la mayor crisis sufrida por el mundo capitalista" (Sábato, 1980: 78). En este sentido, el análisis de Sábato logra ubicar el debate allí donde las cuestiones de la libertad de comercio y circulación de granos y

que éste pueda tomar las medidas para fiscalizar y estudiar el comportamiento de las nuevas variedades en comparación con las existentes en la zona. Ley № 12.253. Capítulo "Fomento de la genética" (1935). 
semillas se ponen en juego, allí donde las características de las técnicas de gobierno en torno al agro cobran visibilidad y comienzan a mutar.

Así como a comienzos del siglo XX el centro del debate relativo al agro giraba en torno a la necesidad de una mayor intervención por parte de los gobiernos, a mediados de dicho siglo el problema del agro comienza a ser percibido de un modo distinto. En el contexto del golpe cívico-militar que derroca a Juan Domingo Perón en septiembre de 1955, comienza a escucharse con más fuerza la idea de que los problemas del agro radican en el errado intento del peronismo de subvertir la economía natural del país y propugnan el retorno a una estrategia económica basada en el librecambio (Lázzaro, 2005). De todos modos, de ambas propuestas sólo la segunda será llevada a cabo. Retornar a la economía natural del país, es decir a una economía basada fundamentalmente en la exportación de granos ya no parecía ser viable ni tener el consenso necesario. El hecho de que estos planteos a favor del librecambio hayan emergido en el contexto de la segunda posguerra no constituye un dato menor. Pero para poder comprenderlo en mayor profundidad debemos vincularlo a una serie de hechos singulares que tendrían lugar en la misma época, especialmente, en el ámbito de la ciencia y de la política internacional íntimamente relacionados a la agricultura, a la escasez y a la semilla.

A fines de los años 40, el joven especialista en Patología Vegetal, Norman Borlaug, se encontraba trabajando en un proyecto de la Fundación Rockefeller para paliar el hambre en el ámbito rural de México. Fue en dicha época que el investigador norteamericano cruzó una variedad de trigo local con variedades enanas japonesas y obtuvo nuevas plantas de trigo más productivas, que podían resistir la aplicación de mayor cantidad de fertilizantes y crecer vigorosamente sin doblarse. Mediante este procedimiento incorporó los genes del enanismo en la variedad de trigo local, los cuales permitían el desarrollo de tallos más cortos y fornidos. Estas variedades utilizaban la mayoría de su energía en la producción y llenado de granos y relativamente poco en el crecimiento en altura y en la producción de hojas, y respondían mejor a los fertilizantes que las variedades tradicionales. Los cultivadores adoptaron estas variedades semi-enanas muy pronto, especialmente en lugares con acceso a irrigación, y obtuvieron rendimientos muy superiores a los de las variedades tradicionales. Este descubrimiento, que daría comienzo a lo que posteriormente se conocería como la "Revolución Verde", lo llevaría a Borlaug a recibir el premio Nobel de la Paz en 1970 y se enmarca en aquello que el antropólogo colombiano, Arturo Escobar, denominó el "descubrimiento" de la pobreza masiva del Tercer Mundo (Escobar, 1998) y en aquello que podríamos pensar como el indicio de la emergencia de un nuevo régimen de verdad. Es decir, una mutación del discurso bélico de las grandes potencias mundiales, que había predominado hasta la Segunda Guerra Mundial, hacia el "campo social" y hacia un nuevo territorio: Asia, África y América Latina; y la necesidad de prevenir un acontecimiento de nuevo tipo vinculado al "desmesurado" crecimiento demográfico, más que a la pobreza y el hambre, aunque íntimamente vinculado. Tanto el proyecto de la Fundación Rockefeller en el cual Borlaug trabajaba como su descubrimiento adoptan otros matices al ser analizados en relación a esta "guerra contra la pobreza" de los países en vías de desarrollo. Walter Kugler, quien fuera Director General Asistente de 
Investigaciones Agrícolas del Instituto Nacional de Tecnología Agropecuaria de la Argentina durante 1967-68 y Coordinador General del Programa Cooperativo de Mejoramiento de Maíz y Trigo INTA-CIMMYT (Centro Internacional de Mejoramiento de Maíz y Trigo) durante 1968-70, mantuvo una estrecha relación con Norman Borlaug, quien en ese entonces se encontraba a cargo del CIMMYT en México. Fruto de esta relación fue la introducción de los trigos enanos (o mexicanos) que posibilitaron la fertilización, la promoción del uso de fertilizantes avalados por los resultados de una red de ensayos montados a tal efecto, la creación del primer banco nacional de germoplasma con ambiente regulado y la recolección de material genético de maíz, maní y papa en centros de origen en Argentina. Es decir, la difusión del uso de semillas obtenidas por cruzamiento o híbridas, cuya investigación y producción en el país se encontraría a cargo de los organismos públicos hasta la década de 1960.

Por otra parte, en el año 1944 el médico e investigador canadiense, Oswald Avery, demostró que la herencia genética residía en el ADN. En 1953, James Watson y Francis Crick lograron determinar la estructura del $A D N$ al proponer que se trataba de una molécula con forma de doble hélice. En 1965, un grupo de investigadores liderado por David Chilton Phillips descubren las enzimas de restricción, unas proteínas capaces de cortar la molécula de ADN en determinados lugares; éstas comienzan a ser utilizadas para obtener fragmentos de ADN. Sin embargo, es recién en 1972 cuando Mertz y Davis y Paul Berg, de la Universidad de Stanford, utilizan por primera vez dichas enzimas de restricción y otra enzima, llamada ADN-ligasa, para crear la primera molécula de ADN recombinante, o sea una molécula de ADN formada por trozos provenientes de distintas fuentes, de distintos organismos. Un año más tarde, en 1973, los genetistas Herbert Boyer y Stanley Cohen, de la Universidad de California en San Francisco, cortaron el gen de un virus y lo pegaron en una bacteria. Cuando la bacteria se reprodujo, hizo copias del gen del virus. Los investigadores demostraron que las bacterias podían convertirse en fábricas de proteínas. Al recombinar genes de esta manera, Cohen y Boyer fundaron la tecnología de "recombinación" del ADN y crearon el primer organismo transgénico. La primera semilla transgénica sería creada 10 años después. Si la búsqueda de una mayor homogeneidad y uniformidad de las semillas pampeanas de comienzos del siglo $\mathrm{XX}$, así como los signos de agotamiento de dicha producción, pueden enlazarse con la promulgación de la "Ley de Granos" № 12.253 del año 1935, entonces la creación y difusión de un nuevo tipo de semillas (obtenidas por cruzamiento o híbridas), la recuperación del sector y la percepción de que las políticas gubernamentales debían tener una menor incidencia en el agro puede concebirse como una serie de fenómenos íntimamente vinculados a la promulgación de la "Ley de Semillas y Creaciones Fitogenéticas" № 20.247 del año 1973. Su análisis nos permitirá comprender esta última serie en mayor profundidad.

El 29 de enero de 1971, el entonces Secretario de Estado de Agricultura y Ganadería, ingeniero Walter Kugler, mediante la Resolución №253, creó una Comisión de Estudio integrada por representantes de los distintos sectores oficial y privado para la elaboración del proyecto de ley cuyo trabajo culminaría con la promulgación el 30 de marzo de 1973, de la "Ley de Semillas y Creaciones Fitogenéticas" $N^{\circ}$ 20.247. La participación de representantes de sectores privados se enmarca en un proceso de mutación del accionar gubernamental, que ya hemos mencionado, y que podemos rastrear con mayor claridad a partir de 1956 con la creación del Instituto Nacional de Tecnología Agropecuaria (INTA) $)^{7}$ A esto debemos agregarle dos hechos de gran

\footnotetext{
${ }^{7}$ EI INTA, un organismo de carácter autárquico, comienza efectivamente su labor en el año 1958, durante el gobierno de Arturo Frondizi (1958-1962), con algunas de las funciones del Ministerio de Agricultura y las Estaciones Experimentales existentes que le fueron transferidas. Dichas Estaciones Experimentales eran unas 11 y, en poco tiempo, se creó la mayoría de las restantes. Un aspecto sumamente relevante es que además del Consejo Directivo, integrado por el Presidente, el Vicepresidente y un Vocal designados directamente por el Ministerio de Agricultura, y representantes de las entidades nacionales de productores y de las facultades de
} 
importancia. En primer lugar, el establecimiento del "régimen de pedigree cerrado" para los criaderos privados, en 1959, ya que a partir de ese momento dejó de ser necesario revelar las fórmulas híbridas y fiscalizar los lotes de semilla parental, estableciendo una forma de protección de los derechos de propiedad intelectual (DPI) conocida como secretos industriales o comerciales. En segundo lugar, en 1962 tuvo lugar la declaración de utilidad pública de las líneas endocriadas (que constituían los híbridos descubiertos por los organismos públicos). Esto implicó que comenzara a regir el "régimen de pedigree abierto" para las instituciones públicas, con lo cual éstas debían revelar sus fórmulas, fiscalizar los lotes de semilla parental y ceder las líneas endocriadas a quien lo solicitara, ya que eran considerados bienes públicos. De este modo, se crearon las condiciones para la apropiación privada de creaciones públicas y el desarrollo de la industria semillera en materia de híbridos de maíz (Rossi, 2007). Libertad y control, así podríamos resumir esta serie de nuevos procedimientos, discursos e instituciones emparentadas con una economía de poder que procura producir, insuflar e incrementar las libertades, al mismo tiempo que extender los mecanismos de control, coacción y coerción.

La "Ley de Semillas y Creaciones Fitogenéticas" № 20.247 puede problematizarse en el marco de un proceso de desmantelamiento, no absoluto, de ese sistema jurídico disciplinario de tipificación, selección y fiscalización de la semilla que había comenzado a montarse en la década del 30 . Un proceso que, en íntima vinculación con el surgimiento de nuevas disciplinas científicas (tales como la cibernética y la biología molecular), nuevos descubrimientos (tales como las semillas híbridas que marcarán el comienzo de un nuevo vínculo entre ciencia y agricultura) y nuevas prácticas agrícolas (tales como la fertilización o el uso del tractor que reemplazará al peón), también se enlaza con el nacimiento de una nueva noción de semilla, de potencia nutritiva, de vida vegetal.

Descubrir, crear y desarrollar mejores semillas, así como controlar su calidad, han sido las actividades más antiguas y continuas del Ministerio de Agricultura y Ganadería, pero, la notable evolución producida en los últimos tiempos ante el rápido progreso de las ciencias genéticas, las mayores exigencias de la agricultura tecnológica moderna, la multiplicación y difusión de semillas por empresas especializadas que aplican técnicas altamente avanzadas y fuertes insumos, determina que resulte en muchos casos insuficiente la legislación vigente en la materia, basada en la Ley № 12.253, Capítulo Fomento de la Genética. ${ }^{8}$

Antes se trataba de tipificar, seleccionar y fiscalizar la semilla; ahora ésta puede ser descubierta, creada y desarrollada. En tiempos de la agricultura

Agronomía y Veterinaria nacionales, la institución contaba con Consejos Asesores de las Estaciones Experimentales y de las Agencias de Extensión Rural, integrados por representantes de las diversas organizaciones locales de productores, de los bancos vinculados a lo agropecuario y de los gobiernos provinciales.

\footnotetext{
${ }^{8}$ Ley de Semillas y Creaciones Fitogenéticas № 20.247. Buenos Aires, 30 de marzo de 1973.
} 
tecnológica moderna, las regulaciones vigentes resultaban insuficientes 0 , mejor dicho, inadecuadas. Esta carencia intentará ser suplida a través de la creación, en 1978 (año en que se dicta el primer Decreto Reglamentario de dicha Ley), del Servicio Nacional de Semillas (SENASE) como órgano de aplicación y, dentro de éste, del Registro Nacional de Comercio y Fiscalización de Semillas (RNCFS), el Registro Nacional de Cultivares (RNC) y el Registro Nacional de Propiedad de Cultivares (RNPC). Este último será el organismo que otorgará los Títulos de Propiedad (DOV) sobre las creaciones fitogenéticas que demuestren ser nuevas, homogéneas, estables y posean una denominación adecuada. La inscripción en este registro le permitirá a los criadores el cobro de regalías por la inversión en innovación y desarrollo de nuevas variedades (Brieva, et. al, 2008). Por otra parte, con anterioridad al año 1978, y en aplicación del capítulo $4^{\circ}$ de la ley en cuestión, se constituyó la Comisión Nacional de Semillas como organismo asesor del Secretario de Agricultura y Ganadería y del propio Organismo de Aplicación de la Ley. Esta Comisión Nacional resulta de particular importancia dado que estaba integrada por representantes de todos los sectores de la actividad semillera, tanto del ámbito oficial como privado, lo cual implicaba que toda medida a adoptarse en materia de semillas fuera estudiada y evaluada previamente por dichos sectores.

Semilla de alta calidad es factor básico para una eficiente agricultura, capaz de satisfacer las crecientes demandas de alimentos y de otros productos derivados de las plantas, señala el segundo párrafo del texto de la ley. Nuevo régimen de verdad al interior del cual la naturaleza puede ser creada o descubierta por lo humano y donde el hombre/especie emerge como crecimiento irrefrenable, desmesura y peligro; acontecimiento a ser evitado. Así como las semillas de las cuales la nueva ley da cuenta pueden ser no sólo apropiadas sino también creadas, la Ley también tiene dicho atributo al realizar una distinción novedosa entre "semillas identificadas" y "semillas fiscalizadas". En primer lugar, a partir de la Ley toda semilla a ser comercializada, definida como toda estructura vegetal destinada a siembra o propagación (lo cual incluye, además de las semillas botánicas, a todos los órganos de propagación agámica ${ }^{9}$ ), debe estar debidamente rotulada, es decir, que debe incluir en su marbete ciertos datos sobre el responsable de la rotulación (nombre, dirección y su número de inscripción en el Registro Nacional de Propiedad de Cultivares, creado por la misma ley), sobre la especie de la cual se trata, el nombre de la variedad, la información sobre su calidad (poder germinativo y pureza físicobotánica), los datos sobre la campaña de producción, el peso neto y el origen de la misma. Estas semillas serán denominadas "identificadas". Las "semillas fiscalizadas" serán aquellas que además de cumplir con esta rotulación hayan sido sometidas a control oficial durante las etapas del ciclo de producción. Estas semillas creadas por la nueva ley implicarán la muerte o desaparición de aquello que pasará a denominarse post-mortem como "semilla común", aquella sin exigencias de rotulación y que, por lo tanto, no daba garantías de identidad y calidad al productor que la adquiría (Harries, Ripoll, 1998). La creación de estas semillas estará vinculada, como hemos visto, a noveles instituciones que

\footnotetext{
${ }^{9}$ Es decir, aquellos sin gametas (sin células reproductivas). En los vegetales hay muchas formas de reproducción en las que no intervienen órganos sexuales (al igual que en el caso de los animales no vertebrados).
} 
estarán dotadas de nuevas capacidades, la más importante de las cuales será el ejercicio del poder de policía. Es decir, la autoridad de acceder a todo lugar o depósito donde existan semillas, de requerir cualquier documentación relativa a las mismas y de intervenir e inmovilizar cualquier partida de semilla en presunta infracción a la ley; asignándose como instrumento aquello necesario para que las actividades relativas a la semilla alcancen una integración efectiva al Estado, a sus fuerzas, al desarrollo de éstas.

\title{
Desplazamientos
}

\begin{abstract}
"Tecnología digital, software, sensores remotos, georreferenciación, mapas de rendimiento e imágenes satelitales son términos cada vez más comunes en el agro argentino".
\end{abstract}

Lorenzatti, S.; "El futuro ya está aquí",

Clarín Rural Revista, noviembre de 2007

Cuando a mediados de la década del noventa la semilla de soja modificada genéticamente fue liberada al mercado, la mecanización agrícola, que tanto había preocupado a los representantes del Estado nación, no constituía más que un recuerdo. Sin embargo, un acontecimiento resulta inconcebible sin el otro. La semilla transgénica, ese organismo vegetal producto del accionar de un conjunto de hombres contratados por una empresa multinacional, será esparcida a lo largo de un ámbito rural que con este hecho terminará de recuperarse de una de sus peores crisis. Aquel Estado nación, preocupado por la mecanización, también pasaría a ser del orden del recuerdo después de que tuvieran lugar los siguientes procesos: desregulación de la producción agropecuaria y del comercio interno e internacional, disolución o desarticulación de los principales organismos del Estado encargados de la orientación y supervisión de las actividades agropecuarias y agroindustriales (entre ellos la Junta Nacional de Granos y la Junta Nacional de Carnes), eliminación de las políticas regulatorias de fijación de cuotas de producción y de garantía de precios mínimos para los productores, pérdida de espacio de la actividad de investigación, extensión y capacitación del Instituto Nacional de Tecnología Agropecuaria.

Sin embargo, esta virtual desaparición de los mecanismos de control, esta "radical desregulación" puede ubicarse en el plano de los desplazamientos. Ambos términos, "control" y "desregulación", hacen alusión al ámbito de la producción. Una producción agropecuaria y un paisaje que se habían desarrollado durante décadas: la agricultura de la tierra, el alambrado y el gaucho; la semilla, el trabajador civilizado y el tractor. Pero tanto la desaparición de los mecanismos de control de la producción agropecuaria, como su radical desregulación son síntomas de una ausencia, señales de una gran transformación a través de la cual muchos de los términos y parámetros de aquel paisaje moderno en crisis ya no tendrán asidero en el ámbito rural. Pero no desaparecerán por completo sino que se desplazarán en sintonía con aquella mutación del capitalismo que Lefebvre analizó en términos de producción de espacio o urbanización de la realidad, es decir, la transformación a escala mundial de los patrones de desarrollo y el desvanecimiento del trabajo como factor de previsibilidad y cohesión. En el caso de la producción agropecuaria argentina, este cambio puede leerse a partir de una serie de hechos singulares ocurridos en el año 1984, durante el cual la producción agropecuaria alcanzaría su récord de crecimiento, para luego derrumbarse de la mano de la caída de los precios agrícolas en los mercados internacionales. En forma posterior a esta crisis tendrá lugar la creación de una serie de organismos supranacionales, el más importante de los cuales será la Organización Mundial del Comercio. Para que la Argentina se recupere de dicha situación deberán pasar unos diez años, a lo largo de los cuales tendrá lugar una radical reestructuración del ámbito rural. Es a la luz de la misma que las características del "nuevo modelo del agro" pueden ser comprendidas en mayor profundidad.

Hacia fines del año 2007, el diario Clarín publicaba el primer número de una revista dedicada al ámbito rural. Es decir, una revista que se sumaba al Suplemento Rural publicado cada sábado por el mismo diario. El título de tapa era "La Ciber Agricultura" y la imagen que 
ilustraba la misma no era una fotografía sino una infografía, es decir, una imagen creada en una computadora. En términos estéticos, probablemente este haya sido el aspecto más distintivo de la misma. En la tapa de este primer número se pueden observar algunas cuestiones importantes que hacen a la propuesta de la revista y que nos servirán para comenzar a desovillar la madeja del "nuevo mundo rural". Una planta aparece en primerísimo plano, y a su alrededor una serie de elementos conectados entre sí y hacia el interior de la planta, como si fueran la salvia de la misma, aquello que le da vida: un tractor moderno, una computadora portátil, dos silos, un molino, una fábrica, una trilladora, un celular, un satélite y la tierra. Una planta enorme, fuera de escala, y una ausencia, el hombre. El primer número de la Revista Rural tiene por objetivo presentar aquello que en el segundo número cobrará toda su dimensión, el "nuevo modelo del agro". Un modelo cuyo paisaje no puede ser fotografiado sino ilustrado a través de un ordenador. Un paisaje que está y no está, que en cierto modo pertenece al orden de lo imaginario o del relato. Un paisaje desmaterializado e inasible. Un paisaje virtual que nos permite ver al interior de la planta, del mismo modo en que los científicos se internan en el ADN de la semilla para modificarla, para crearla. Una planta genéticamente modificada que requiere de otros elementos para poder abrazar la vida, ser rentable: grandes extensiones de tierra, un potente agroquímico, una serie de nuevas máquinas, agua, sol y humedad. Pero si la agricultura ha podido llegar a este grado de complejidad-simplicidad es porque antes ha corrido sangre. La sangre de ese hombre de campo que en la década del 60 resultaba necesario disciplinar, ese otro tipo de vida (humana) que ahora resulta difícil de hallar, que ya no importa ${ }^{10}$. Este nuevo paisaje, en principio entendido en términos netamente visuales, se enuncia acerca de un desplazamiento de otro orden. Desplazamiento de la regulación y el control hacia problemas que ya no hacen al disciplinamiento de los hombres/cuerpos (el hombre frente a la máquina, lo civilizado e instruido) sino a la regulación de los hombres/especie (la proliferación de la vida y la regulación de los peligros) a través de la intervención sobre el medio. Movimiento no excluyente que se experimentará como crisis, éxodo, exclusión y empoderamiento y que orientará, a través de una serie de mecanismos y de la aplicación de un conjunto de nuevas tecnologías, la regulación y el control hacia el orden de lo viviente, entendido como planta, animal y semilla.

Es en este contexto que podemos pensar la trascendencia actual de lo aleatorio e impredecible. Es decir, de aspectos que si bien siempre han caracterizado al ámbito rural, ahora, que la intervención directa sobre la vida resulta posible, adquieren otra dimensión. Lo aleatorio e impredecible es narrado en esta primera Revista Rural como un peligro en relación a lo viviente, que ahora es semilla, planta y población. El "productor Amuchástegui", en aquella primera nota ("El futuro ya está aquí"), señala lo siguiente:

"[...] A esta primera capa de información se le agregan otras, como la utilización de cartas de suelos digitales (identifican los diferentes tipos de suelos en una región), imágenes satelitales, fotos aéreas, e incluso "la simple búsqueda e identificación de un campo en el Google Earth", enfatizó. El resultado final es la identificación y cuantificación de la variabilidad ambiental [...]".

\section{"Así, en 1999 incorporan monitores de rinde con GPS en las cosechadoras, lo que les permitió 'cuantificar la heterogeneidad espacial de los lotes y encontrar las relaciones causa efecto entre variables medidas y el resultado obtenido, en términos de rendimiento y calidad', destacó".}

(Lorenzatti, Santiago. 2007. El futuro ya está aquí. Clarín Rural Revista, La Ciber Agricultura. Edición № 1. Buenos Aires, p. 6)

\footnotetext{
10 “(...) es cierto que hay 150.000 productores menos, que se fundieron en la década pasada. $O$ sea que esta competitividad de la soja se hizo con sangre. No fue una fiesta. ¿Y qué es la competitividad en la soja? Es la suma de innovaciones tecnológicas y organizacionales que pusimos en el campo durante los últimos 15 años". Gustavo Grobocopatel (2003). "La soja es causa nacional". Cita tomada del siguiente artículo: Hernández, Valeria (2007). El fenómeno económico y cultural del boom de la soja y el empresariado innovador. Desarrollo Económico, vol. 47, № 187.
} 
"Identificar y cuantificar la variabilidad ambiental", establecer probabilidades, controlar lo heterogéneo e impredecible. El campo de acción sobre lo aleatorio no tiene límites ya que este sólo puede explicarse en razón de la intervención del azar. Las nuevas tecnologías, que siguiendo a ciertos autores podríamos aunar bajo la noción de "ciberciencia" ", constituyen mecanismos de regulación de toda esa serie de fenómenos tan importantes para "el nuevo modelo del agro" y que sólo pueden controlarse mediante un cálculo de probabilidad o, más ampliamente, a través de la estadística. Podríamos decir que variabilidad y heterogeneidad son los nombres de los nuevos peligros a regular. Volviendo sobre el par complejidad-simplicidad para caracterizar al ámbito rural pampeano del siglo XXI, resulta interesante la posibilidad de esbozar una genealogía de la "ciberciencia", por un lado, y de la "biología molecular", por otro. La primera es aquella que, precisamente, buscará lidiar con lo complejo, la sobreproducción de información. En su génesis debemos mencionar dos hechos fundamentales, la creación del ordenador, primero, y del análisis de sistemas, después; nacimientos que tuvieron lugar durante la segunda guerra mundial en íntima vinculación con dicho contexto, es decir, con un momento en el cual la comunicación estaba al servicio del control. La biología molecular, en cambio, emprenderá el camino inverso hacia la búsqueda de la esencia de la vida en "organismos tan rudimentarios y simples que fueran inmunes al caos mistificador y recalcitrante de organismos complejos más elevados" 12 y acabará por descubrir la estructura del ADN a comienzos de la década del cincuenta. Esta estrategia llevó a los biólogos moleculares al estudio de la vida en tubos de ensayo y cápsulas de Petri poblados por formas de vida que parecían lo suficientemente simples para preservar la linealidad de códigos sencillos y mensajes al estilo de los telegráficos. Si bien las computadoras terminarán utilizándose en ambas disciplinas, resulta interesante la sugerencia de que el "nuevo modelo del agro" aúna ambas búsquedas, el control de la complejidad a través de la aplicación de la informática y la cibernética al medio, y la manipulación de la esencia de la vida mediante la biotecnología. En este sentido, podemos pensar que el par complejidad-simplicidad es profundamente paradojal y sintetiza un aspecto clave de las narrativas y estéticas actuales en torno a lo rural: la noción de que la producción llevada acabo con el nuevo "paquete tecnológico" (conformado por la semilla transgénica de soja, el glifosato y la siembra directa) es mucho más simple que la producción agrícola tradicional ("no hace falta pensar, ni tener conocimientos previos"), al mismo tiempo que lo complejo radica en los componentes del mismo y es desplazado hacia el ámbito de la ciencia (fundamentalmente, los laboratorios) y el mundo empresarial (los pools de siembra y grupos asesores, compuestos por financistas y profesionales). Decíamos previamente que el desplazamiento de la regulación y el control hacia los problemas de los hombres/especie (la proliferación de la vida y la regulación de los peligros) a través de la intervención sobre el medio constituía un movimiento no excluyente que se experimentaría como crisis, éxodo, exclusión y empoderamiento. En este sentido, el par al cual estamos haciendo referencia es símbolo implícito de éxodo y símbolo explícito de empoderamiento. El éxodo, en la región pampeana, es el de aquella vida que ya no importa, la de los trabajadores rurales y los pequeños productores que debieron abandonar o arrendar sus tierras porque ya no podían vivir de ella. El empoderamiento es el de quienes sobrevivieron a la crisis, o nunca la experimentaron, el de los nuevos habitantes de los barrios privados y clubes de chacras, aquellos que gozaron del despegue del precio internacional de los commodities. El éxodo es la sangre traslúcida que Gustavo Grobocopatel nombró en el año 2003, ríos de sangre que corren a través de los surcos milimétricamente separados de la soja transgénica y se funden con el glifosato. Es la muerte, pero una forma de la muerte que es posible de ser regulada y que forma parte del mismo mecanismo que regula lo viviente, una cifra más del Censo Nacional Agropecuario que cada diez años nos cuenta cuántos productores han sido desplazados. El empoderamiento, término venerado por el Banco Mundial, es imagen y tapa, es el "poder-

11 "Podría considerarse que estas disciplinas -teoría de la información, cibernética, análisis de sistemas, investigación operacional y ciencia de la computación- son emprendimientos vagamente conectados que comparten una tarea común (el análisis de sistemas complejos), un vocabulario conceptual para abordarla (retroalimentación y comunicación: causalidad circular) y un modo de representación (de los sistemas complejos como redes o circuitos interactuantes) (...) me referiré a estas disciplinas con el término unitario de ciberciencia." Fox Keller, Evelyn (2000). Lenguaje y vida. Metáforas de la biología en el siglo XX. Manantial: Buenos Aires.

12 lbíd., p. 90. 
hacer" de la impotencia y la dependencia. Es el productor con anteojos de sol y computadora portátil bajo el brazo, el tractor con piloto automático y GPS, son las miles y miles de hectáreas de perfección estética sojera, el aumento de la rentabilidad... el futuro que "ya está aquí". 
El empoderamiento es también y, sobre todo, paisaje. Es decir, se trata de un fenómeno que resulta fértil pensarlo a la luz de la movilización de una serie de estéticas y discursos que construyen un lazo simbólico y material de nuevo tipo, ya no entre la sociedad y la naturaleza, sino entre la población y el medio. El medio, esa noción que pasó de la mecánica a la biología en la segunda mitad del siglo XVIII, puede ser entendido como un conjunto de datos y una cantidad de efectos masivos que afectan, no a quienes residen en él, sino a quienes a él se encuentran de algún modo vinculados. "Es un elemento en cuyo interior se produce un cierre circular de los efectos y las causas" (Foucault, 2006: 41), por ejemplo, cuantas más hectáreas se siembran con soja transgénica, más trabajadores deben abandonar el ámbito rural, más aumenta la población urbana y las cifras de desocupados y pobres. Con el mismo punto de partida, podríamos decir que cuantas más hectáreas se siembran con soja transgénica, más aumenta la productividad, es decir, más "alimentos" se producen y menos personas mueren de hambre en el mundo. El medio, entonces, constituye un campo de intervención en el cual ya no se afecta a los individuos, como un conjunto de sujetos de derecho capaces de acciones voluntarias, sino a una población. A diferencia del modo en que Foucault planteó el concepto de medio, como aquello que afecta a una multiplicidad de individuos que están biológicamente ligados a la materialidad dentro de la cual existen, en el caso del "nuevo agro pampeano" esa materialidad ya no es del orden de la experiencia material tradicional. La experiencia misma del ámbito rural ha sufrido una profunda mutación que sólo podrá ser entendida en su complejidad al componerla con el fenómeno de los "clubes de chacra". Es en este sentido, que el paisaje, en tanto forma simbólica y material de mediación, pasa a desempeñar aquí un papel fundamental, no porque suplante a una experiencia imposible de concretar, sino porque, precisamente, inaugura una experiencia de nuevo tipo que podríamos denominar "visual-virtual" entre un medio artificial y natural, y una población, tejida de relaciones sociales y políticas, que funciona como especie.

La experiencia "visual-virtual" que el paisaje sojero, la ciberciencia y la biotecnología vienen a inaugurar supondrá la movilización de una serie de discursos e imágenes vinculadas a aquello que ya hemos analizado como "empoderamiento". Se tratará de una conjunción de lo visual y lo virtual en tanto, si bien podemos decir que se trata de una experiencia del orden de lo que se experimenta a través de la vista, la misma supone un tipo de materialidad y concreción propio de lo virtual. Una nueva forma de estar y de habitar la realidad:

"Estos datos están siendo registrados desde febrero de 2000 mediante un sensor ubicado en un satélite de la NASA, que sobrevuela los establecimientos cada 16 días y toma información detallada en superficies que abarcan sólo 5,3 hectáreas". (Lorenzatti, Santiago. 2007. En ganadería los satélites miden hasta el campo. Clarín Rural Revista, La ciber agricultura. Edición № 1. Buenos Aires, p. 6)

Si en cada cultura podemos hallar una jerarquización de los sentidos a través de los cuales el espacio es experimentado, en el caso del "paisaje sojero" el sentido por excelencia es la visión (Tuan, 2001). Nuestros ojos al observar un paisaje buscan puntos donde descansar, pero el "paisaje sojero", luego de haber expulsado lo viviente (humano), carece de dichos puntos. Por ello, la composición de las imágenes en que dicho paisaje aparece suelen ubicar elementos que sirven de marco, primeros planos de los surcos que generan una perspectiva más atractiva u objetos desconcertantes:

"Para Javier Amuchástegui, de Tecnocampo -empresa agropecuaria del norte cordobés- "la agricultura de precisión te ayuda a abrir los ojos, porque permite comenzar a diferenciar y cuantificar situaciones a campo que de otra forma serían difíciles de detectar". Así se abre el camino para una agricultura a medida". (Lorenzatti, Santiago. 2007. El futuro ya está aquí. Clarín Rural Revista, La Ciber Agricultura. Edición № 1. Buenos Aires)

Es en la preeminencia de este sentido donde también radica la posibilidad de lo virtual o, mejor dicho, precisamente porque se trata de una experiencia virtual es que la visión es el principal sentido capaz de dar comienzo a la misma. Entonces, podríamos decir que esas 
imágenes o datos recabados por el satélite de la NASA constituyen "un retrato postmoderno" en la medida en que se trata de "un constructo desnaturalizado de primer orden". Eso que se ve o percibe como si alguien hubiera estado allí, al igual que las imágenes tomadas del Google Earth, en realidad son un producto de un satélite que "envió imágenes digitalizadas de vuelta a un mundo de transformadores y creadores de imágenes situados en un lugar distante llamado tierra" (Haraway, 1995: 380). Si la noción de "realidad virtual" da cuenta de una realidad perceptiva sin soporte objetivo, podríamos decir que estos retratos postmodernos constituyen una realidad percibida, fundamentalmente, a través de la vista con un soporte cuya objetividad desconocemos, aunque a los fines de nuestro análisis dicha falta de objetividad no constituya un problema.

Hay otro aspecto que caracteriza a esta mirada que guía la experiencia visual-virtual y es aquello que podríamos denominar el tratarse de una "mirada desde arriba" (de Certeau, 2007). La ubicación de esta mirada no sólo tiene implicancias sobre aquello que observamos, sino también sobre el modo en que lo hacemos. Mirar desde arriba, ya sea desde un satélite 0 un avión, es, en primer lugar, una visión mediada por algún tipo de máquina, una reconstrucción de lo existente, cuando no una simple creación que guarda algún tipo de virtualidad, que construye realidad. La afección por las alturas también implica una desafección por lo sensorial, lo material, lo humano, aquello del orden de la corporalidad, que es olvidado, puesto en suspenso y condición fundamental de lo anterior. En los sembradíos de soja no hay cuerpos, hay organismos vivos. La altura constituye asimismo un instrumento más de control, la posibilidad de percibir la totalidad. El "paisaje sojero" de la Revista Rural nos invita a experimentarlo desde arriba, es decir, desde el lugar en el cual puede observarse y disfrutarse en toda su magnitud, su orden y su perfección. También es desde arriba que la mayoría de las nuevas tecnologías nos invitan a controlar y regular los peligros de la heterogeneidad, la variabilidad y, muy especialmente, las temidas y supuestamente superadas plagas. En síntesis, aquellos fenómenos de serie cuya aleatoriedad se torna necesario regular en este nuevo ámbito rural. Esto puede observarse en el modo en el cual varias publicidades de laboratorios y empresas del agro optan por complementar los planos aéreos con primeros planos de plantas o de insectos, alterando por completo la perspectiva, en búsqueda de la personificación a escala gigante de aquello que constituye un peligro para la rentabilidad de la producción, para la planta y, en consecuencia, para el "bienestar de la población".

Para correr la carrera, la agricultura tiene estrellas rutilantes saliendo de las gateras. Como los "genes apilados" que recién asoman en las Pampas y ya prometen exitosas batallas simultáneas contra plagas y enfermedades. (Bártoli, Mauricio y Patricio Downes. 2008. Cómo será el agro que viene. Clarín Rural Revista, El nuevo modelo del agro. Edición № 2: 5. Buenos Aires)

Entonces, podemos decir que la heterogeneidad de los suelos, la variabilidad ambiental, las plagas y las enfermedades constituyen viejos problemas que en este nuevo agro del siglo XXI son claramente concebidos como peligros aleatorios a ser regulados, enemigos. Dicha regulación requerirá de una permanente e incesante super-producción de información que sólo sería posible en esta nueva dimensión a partir de la aplicación de la "ciberciencia" al ámbito agrícola. Mapeos y re-mapeos, datos y cifras que se generan al instante, y herramientas tecnológicas que permiten cálculos simultáneos a la siembra o cosecha.

"De este modo, en la actualidad existe una serie recopilada de ocho campañas, con datos mensuales, anuales y espaciales derivados de imágenes satelitales que combinados con información climática, permiten reconocer la radiación absorbida por una pastura o verdeo, y estimar su productividad". (Lorenzatti, Santiago. 2007. En ganadería los satélites miden hasta el campo. Clarín Rural Revista, La ciber agricultura. Edición № 1. Buenos Aires, p. 6)

"El monitor de rendimiento es un equipamiento que permite medir y grabar la productividad de un cultivo a medida que se cosecha", comentó Andrés Méndez, especialista en agricultura de precisión [...]. Y, si se le adiciona un GPS, "podemos 
obtener esos datos geoposicionados y ordenados", agregó. (Lorenzatti, Santiago. 2007. El futuro ya está aquí. Clarín Rural Revista, La ciber agricultura. Edición № 1. Buenos Aires, p. 5)

Estos datos, estas estadísticas, estas máquinas son un elemento clave del "nuevo paisaje rural", allí donde población y medio se interfieren mutuamente. La superproducción de información, "nunca verdadera" (por oposición a la noción de mapa como lo "eternamente verdadero"), también hace a la forma en que la población experimenta el paisaje (Massey, 2005), como conjunto efímero de datos que nunca logran dar cuenta de la realidad.

Por otra parte, resulta sugerente pensar que la regulación de lo aleatorio, la búsqueda del orden y la perfección, encuentran en la metáfora del campo como fábrica ${ }^{13}$ uno de sus puntos de máxima realización. Imagen tan potente como ficticia que se instala en el plano de lo imaginario y afectivo al traer a escena aquel debate clave de mediados del siglo XX, que se cerraría abruptamente durante la década del noventa para reabrirse a comienzos del siglo XXI; debate acerca de cuál debía ser el motor del desarrollo del país: la agricultura o la industria. Es decir, si debíamos ser un país agro-exportador o uno industrializado. Disputa no menor que supuso, entre otras cuestiones, el desarrollo de una importante clase trabajadora que traería aparejada una alta conflictividad social a partir de una sostenida, pero frágil, industrialización que el gobierno de facto de 1976 eliminaría de raíz. El campo como fábrica es la síntesis perfecta de aquel planteo dicotómico que aún divide las aguas, un intento por obtener un status de igualdad a partir de una imagen virtual que adquiere materialidad en las imágenes de los surcos perfectos e infinitos. Sin embargo, la fábrica constituye una imagen caduca que sólo puede tener sentido en el marco del debate ya señalado y la disputa político-social en torno al mismo. Las fábricas no forman parte de la "sociedad del conocimiento" que la Revista Clarín Rural tanto venera, la de las empresas y los consorcios, los laboratorios y la biotecnología. Sin embargo, en tanto movilización de discursos que, finalmente, permiten la identificación de amplias capas de la población, la metáfora del campo como fábrica resulta altamente efectiva. Reactualización de un debate que divide a la sociedad y realiza un importante aporte a la construcción postmoderna de esa tropografía de lo nacional que mencionábamos al comienzo. Pero el debate sólo puede ser reinstalado en dicho ámbito bajo la condición del desplazamiento de sus términos y de la apelación a aquello que ya no-es, ubicando en el centro de la escena lo que había sido previamente excluido: la industria y su clase obrera, el campo y lo humano. El ingreso de las tecnologías del poder al ámbito de la vida en aquello que solía denominarse "ámbito rural" ha supuesto una mutación de tal magnitud que muchos de los términos y nociones que aún seguimos empleando para su análisis, no resultan efectivos. Será entonces parte de ese mismo ejercicio el crear los términos precisos para dar cuenta y reflexionar acerca de aquello que-es.

\section{Espíritu campestre. Los clubes de chacras como heterotopía.}

"Por sus características, este tipo de emprendimiento poseen el valor agregado de permitir hacer una auténtica vida de campo. Mucho se ha discutido sobre la extensión que tendrían que tener los terrenos para ser considerados chacras y la conclusión final fue que, independientemente de ésta, lo que le otorgaba el sello de fábrica era la filosofía con la que, el desarrollador, encaraba el proyecto".

Marchetti, R.; "Con el espíritu de la vida rural",

Clarín Countries, agosto de 2009

13 "El campo es una fábrica a cielo abierto". Slogan de la " $122^{\circ}$ Exposición de Ganadería, Agricultura e Industria Internacional" del año 2008. 
A comienzos de la década del noventa se planificó el primer complejo que llevaría el nombre de "barrio de chacras". Este desarrollo, que se potenciaría a comienzos del siglo XXI, se encuentra íntimamente vinculado al desarrollo que generó la finalización de la autopista de acceso a la zona oeste de la Provincia de Buenos Aires. Si bien los barrios privados, en general, fueron uno de los emprendimientos clave y símbolo del fin de siglo, los mismos deben enmarcarse en esa serie de mutaciones que comienzan a percibirse a mediados de los ochenta. Pero los "clubes de chacra" no son simples barrios privados, tienen un "valor agregado" que radica precisamente en su ligazón con el ámbito rural. Decíamos previamente que la experiencia misma de lo rural había sufrido una profunda mutación que sólo podía ser entendida en su complejidad al componerla con el fenómeno de los "clubes de chacra". Eso es lo que intentaremos hacer, relacionar lo hasta ahora analizado con este otro ámbito de la experiencia, este otro paisaje que podemos pensar que se encarna en los "clubes de chacra" a modo de heterotopía ${ }^{14}$. Dado que este trabajo forma parte de una investigación más amplia que se desarrolla en el partido de San Andrés de Giles, el corpus relativo a este tema se focalizará en aquellos emprendimientos ubicados en dicha zona del oeste de la Provincia de Buenos Aires, la cual, paradójicamente, constituye uno de los lugares donde más "clubes de chacras" se han instalado.

Pensar los "clubes de chacra" como heterotopías supone ubicarlos en el plano de las utopías efectivamente realizadas, en la medida en que al interior de estos emplazamientos todos los otros emplazamientos reales de la cultura se encuentran representados, cuestionados o invertidos. En este sentido, los "clubes de chacra" serán presentados como la síntesis perfecta del campo y la ciudad:

"El habitar una chacra dentro de La Clara significa que uno puede tener su propia huerta, cultivar lo que se le plazca, montar a caballo y disfrutar de un ambiente puro y natural. Además posee todos los servicios que se brindan en la ciudad, tiene una laguna para practicar deportes acuáticos y no posee áreas comunes". (Puche, Alejandro. 2009. "Estas chacras no son para Giles". Suplemento Countries. Diario Clarín. Buenos Aires)

La combinación de lo natural y puro del campo, junto con la seguridad y la comodidad de la ciudad, supone la movilización de una serie de estéticas que pretenden re-crear experiencias imposibles con reminiscencias de tradición. Es, precisamente, por esta característica que la función primordial de esta heterotopía parecería ser la de compensación. Es decir, la de crear otro espacio, otro espacio real tan perfecto como el nuestro es de imperfecto. Un espacio otro que pueda compensar la pérdida de aquella vida de campo chacarera, por un lado, y la seguridad y el confort urbanos, por otro, a través de la yuxtaposición de múltiples espacios, emplazamientos que son en sí mismos incompatibles. Y el lenguaje nos habla de ello cuando leemos una y otra vez el término "chacras urbanas" en el suplemento Countries. Yuxtaposición de espacios de felicidad en los cuales el tiempo parecería abolirse y reconfigurarse:

Sus desarrolladores han conservado las instalaciones del antiguo establecimiento de campo a las que, debidamente recicladas, incorporaron al área social y de esparcimiento. La casona principal, por ejemplo, cuenta con cinco habitaciones con baño privado, living y sala de estar para huéspedes. Un parque de 35 hectáreas, diseñado en 1896, sirve de marco a esta mansión de estilo colonial y que fue reformada por sus anteriores dueños para pasar las vacaciones en ella. Benquerencia es un ejemplo, en este tipo de emprendimiento, de la armonía entre la tradición y el confort. (Marchetti, R. 2009. "Con el espíritu de la vida rural". Suplemento Countries. Diario Clarín)

\footnotetext{
${ }^{14}$ La noción de hetorotopía fue desarrollada por Michel Foucault en una conferencia dictada en el Cercle des Études Architecturals, el 14 de marzo de 1967. Foucault, Michel. "De los espacios otros". Architecture, Mouvement, Continuité. № 5, 1984. París.
} 
La reconstrucción, con pretensiones de exactitud, de una vida rural tradicional nos remite a la ruptura temporal que subyace con respecto a aquel pasado. Ruptura que también puede pensarse en términos de espiritualización, en la medida en que no se trata de la restauración de experiencias del orden de lo real, sino más bien de aquellas tropografías de la nación que mencionábamos al comienzo de este ensayo. La selección no azarosa de elementos de aquellos mapas imaginarios de identidades argentinas que se conjugan en el "club de chacra", re-actualiza aquel movimiento tan particular de reconstrucción, con fines político-estéticos, de una Edad Dorada ganaderil que nunca existió. Pero aquel movimiento de fines del siglo XIX, comienzos del XX no puede ser comparado linealmente al actual. Doble movimiento de espiritualización, con un siglo de distancia entre uno y otro, que nos ubica en ese preciso lugar en que el "club de chacras" interfiere con el "nuevo modelo del agro". Si las heterotopías son, respecto del espacio restante, una función, entonces el "club de chacras" puede ser concebido como la compensación por la pérdida de la experiencia de la naturaleza y la vida rural, por la expulsión de lo humano de la actividad agrícola que se entrelazaba para dar lugar a una forma de vida. Compensación a modo de re-espiritualización, ya no de una Edad Dorada ganaderil que nunca existió, sino de una vida de campo con huertas orgánicas, espacios para montar a caballo, lagunas artificiales para realizar deportes acuáticos y casas confortables dotadas de calefacción eléctrica, Internet y seguridad privada, que ningún chacarero puede dar fe de haber experimentado.

\section{Interferencia perpetua}

Si las semillas genéticamente modificadas son el "cultivo colonizador" del siglo XXI, entonces cabe preguntarse por las tierras a colonizar. Este ensayo intentó trazar un primer recorrido por las mismas, andar sus senderos aún poco conocidos, circular por sus venas. Así como el alambre estableció los límites de la tierra devenida capital, y el tractor trazó nuevos límites entre lo salvaje y natural, las fronteras que la semilla transgénica viene a demarcar son del orden del avance de lo homogéneo y regular. "Hacer avanzar la frontera agropecuaria", tal como pregonan los pastores de la sociedad rural del conocimiento, supone el predominio de lo viviente vegetal sobre lo viviente humano en lo que solíamos denominar ámbito rural. "Hacer avanzar" es sinónimo de "desplazar", de agriculturización (desplazamiento de actividades "no agrícolas") y pampeanización. Que la Argentina toda se haga "paisaje pampeano", es decir, que predomine la vida vegetal modificada genéticamente, uniforme y homogénea que tantas ganancias ha brindado. Ese "paisaje pampeano", en tanto forma de interferencia entre el medio y la población, que inaugura una nueva experiencia de la actividad agrícola actual. Una experiencia del orden de lo visual-virtual que se ensambla con el "club de chacra" para adquirir todo su potencial, no a modo de espejo sino de heterotopía. Es decir, una nueva noción de paisaje que pasa a constituirse en un aspecto clave a partir del momento en el cual la experiencia corpórea y material se ausenta dejando paso a una experiencia del orden de lo virtual y lo visual. Podríamos pensar que así como el capital intenta despegarse, desplazarse de las fuerzas productivas que lo crean, la producción agropecuaria intenta deshacerse del espacio natural en tanto experiencia vivida de la cual depende para realizarse. Por último, si bien el "nuevo modelo del agro" puede ser rastreado a través de una variedad de discursos de distinto tipo, la propuesta del diario Clarín guarda su singularidad, no sólo por su múltiple vínculo con la nueva vanguardia rural, sino también porque, a diferencia de La Nación (tradicional representante de los dueños de la tierra), su vínculo con el agro es mucho más reciente y de menor arraigo. El hecho de que Clarín se haya transformado en el portavoz de este nuevo modelo no es un dato menor. Por el contrario, nos habla de una nueva configuración o, mejor dicho, de las características del entramado que sostiene y da vida a esta nueva realidad, a estas nuevas prácticas, discursos y tecnologías que conforman el "ámbito rural" actual.

\section{Referencias bibliográficas}

\section{Corpus}

(1935) Ley de granos No 12.253. Capítulo "Fomento de la Genética". 
(1973) Ley de semillas y creaciones fitogenéticas № 20.247, 30 de marzo de 1973.

(1991) Decreto reglamento 2183/91

(2005) Plan Estratégico Biotecnología 2005-2015. Resumen Ejecutivo.

(1965) BARAÑAO, T. V. "La formación de técnicos para la mecanización agrícola". IDIA. Suplemento № 14. Año 1965. INTA, Buenos Aires, p. 23.

(2008) BÁRTOLI, Mauricio y Patricio Downes. 2008. Cómo será el agro que viene. Clarín Rural Revista, El nuevo modelo del agro (2).

(2007) LORENZATTI, Santiago. "En ganadería los satélites miden hasta el campo". Clarín Rural Revista, La Ciber Agricultura (1).

(2007) LORENZATTI, Santiago. El futuro ya está aquí. Clarín Rural Revista, La Ciber Agricultura (1).

(2009) MARCHETTI, R. Con el espíritu de la vida rural. Suplemento Countries. Diario Clarín, 8 de agosto.

(2009) PUCHE, Alejandro. Estas chacras no son para Giles. Suplemento Countries. Diario Clarín. 9 de enero.

(2008) REPETTO, Juan M. Semilleros: el valor de la genética. Clarín Rural Revista, El campo saltó la tranquera (3).

(2009) SCALETTA, Claudio. "La tierra y el paisaje". Página/12. CASH. 31 de mayo.

(2009) SOLANET, Manuel. "Conflictos de la moderna empresa agrícola". Anales. SRA

\section{Libros y ponencias}

(2000) ANDERMANN, Jens. Mapas de poder. Una arqueología literaria del espacio argentino, Beatriz Viterbo Editora, Buenos Aires.

(1920) BUNGE, Alejandro. Los problemas económicos del presente. Buenos Aires.

(1997) CASEY, Edward S. 1997. Preface: Disappearing Places. The Fate of Place. California UP, Berkeley.

(1997) FOUCAULT, Michel, Defender la sociedad, FCE, Buenos Aires.

(2004) FOUCAULT, Michel, Seguridad, territorio y población, FCE, Buenos Aires.

(2000) FOX KELLER, Evelyn. 2000. Lenguaje y vida. Metáforas de la biología en el siglo XX. Manantial, Buenos Aires.

(1995) HARAWAY, Donna. 1995. Capítulo 8. La biopolítica de los cuerpos posmodernos: constituciones del yo en el discurso del sistema inmunitario. Ciencia, cyborgs y mujeres. La reinvención de la naturaleza. Cátedra, Madrid. pp. 347-395.

(1998) HARRIES, Adelaida y Carlos RIPOLL. 1998. Evolución del fitomejoramiento y la producción de semillas en la Argentina. Estructuras oficiales y su marco regulatorio desde comienzos de siglo. Buenos Aires, 24 de agosto.

(1995) HIRSCH, Eric. Introduction. Landscape: Between Place and Space. The Anthropology of Landscape. Oxford UP, Oxford. 
(2005) LÁZZARO, Silvia. El Estado y las políticas agrarias: concepciones y estrategias en el contexto de crisis de hegemonía de la clase dominante (1955-1969). En Lázzaro, Silvia y Guido Galafassi. Sujetos, política y representaciones del mundo rural. Argentina 1930-1975. Siglo XXI editora, Buenos Aires.

(2005) MASSEY, Doreen. The Event of Place. Making and Contesting Time-Spaces. For Space. Londres: Sage.

(2002) MITCHELL, W. J. T. "Imperial Landscape". Landscape and Power. University of Chicago Press, Chicago.

(2003) OBSCHATKO, Edith. El aporte del sector agroalimentario al crecimiento económico argentino, 1965-2000. IICA, Buenos Aires.

(1980) SÁBATO, J. La pampa pródiga. Claves de una frustración. CISEA, Buenos Aires.

(2001) TUAN, Yi-Fu. Visibility: the Creation of Place. Space and Place. The Perspective of Experience. University of Minnesota Press: Minneapolis.

\section{Artículos y ponencias}

(1997) "Los Klein, incuestionables custodios del trigo nacional". Diario La Nación, Suplemento Campo. 16 de agosto de 1997.

(2008) BRIEVA, Susana, CEVERIO, Rocío y Liliana IRIARTE. "Trayectoria de las relaciones socio-técnicas de los derechos de propiedad intelectual en la agricultura argentina: los derechos de obtención de semillas (DOV) en trigo y soja desde principios de los años '70 a la actualidad". Ponencia presentada en las XXI Jornadas de Historia Económica, Prov. de Bs. As., 23-26 de septiembre.

(1918) CÁRCANO, Miguel Ángel. "Organización de la producción. La pequeña propiedad y el crédito agrícola". Revista de Economía Argentina, año 1, № 6.

(2006) COSGROVE, Denis. "Modernity, Community and the Landscape Idea”. Journal of MATERIAL CUTLURE (11).

(2007) DE CERTEAU, Michel. "Andar en la ciudad". Bifurcaciones (7).

(2004) DÍAZ RÖNNER, Lucila. Una aproximación al marco legal pertinente a los productos de la biotecnología agropecuaria. Documentos del Centro Interdisciplinario de Estudios Agrarios (CIEA), № 2, IIHES, FCE, UBA, Buenos Aires.

(1967) FOUCAULT, Michel. "De los espacios otros". Architecture, Mouvement, Continuité. (5).

(2007) HERNÁNDEZ, Valeria. El fenómeno económico y cultural del boom de la soja y el empresariado innovador. Desarrollo Económico (47).

(2007) ROSSI, Daniel. Evolución de los cultivares de maíz utilizados en la Argentina. Revista Agromensajes. Rosario: Facultad de Ciencias Agrarias.

(2010) VOLKIND, Pablo. "Propuestas de reforma frente a un futuro sombrío: los límites del "modelo" agroexportador en la década de 1910. Revista Theomai. 